OPEN ACCESS

Edited by:

Michelle Jillian Devlin, Centre for Environment, Fisheries and Aquaculture Science (CEFAS), United Kingdom

Reviewed by: Neville Scott Barrett, University of Tasmania, Australia Tim Stevens, Griffith University, Australia

${ }^{*}$ Correspondence: E. V. Sheehan emma.sheehan@plymouth.ac.uk

${ }^{\dagger}$ These authors have contributed equally to this work and share first authorship

Specialty section: This article was submitted to Marine Ecosystem Ecology, a section of the journal Frontiers in Marine Science

Received: 23 February 2021 Accepted: 31 July 2021 Published: 23 August 2021

Citation:

Sheehan EV, Holmes LA, Davies BFR, Cartwright A, Rees A and Attrill MJ (2021) Rewilding of Protected Areas Enhances Resilience of Marine Ecosystems to Extreme Climatic Events.

Front. Mar. Sci. 8:671427. doi: 10.3389/fmars.2021.671427

\section{Rewilding of Protected Areas Enhances Resilience of Marine Ecosystems to Extreme Climatic Events}

\author{
E. V. Sheehan ${ }^{\star t}$, L. A. Holmest, B. F. R. Davies, A. Cartwright, A. Rees and M. J. Attrill \\ School of Biological and Marine Sciences, Faculty of Science and Engineering, University of Plymouth, Plymouth, \\ United Kingdom
}

Marine protected areas (MPAs) are employed as tools to manage human impacts, especially fishing pressure. By excluding the most destructive activities MPAs can rewild degraded areas of seabed habitat. The potential for MPAs to increase ecosystem resilience from storms is, however, not understood, nor how such events impact seabed habitats. Extreme storm disturbance impact was studied in Lyme Bay MPA, Southwest United Kingdom, where the 2008 exclusion of bottom-towed fishing from the whole site allowed recovery of degraded temperate reef assemblages to a more complex community. Severe storm impacts in 2013-2014 resulted in major damage to the seabed so that assemblages in the MPA were more similar to sites where fishing continued than at any point since the designation of the MPA; the communities were not dominated by species resistant to physical disturbance. Nevertheless, annual surveys since 2014 have demonstrated that the initial recovery of MPA assemblages was much quicker than that seen following the cessation of chronic towed fishing impact in 2008. Likewise, General Additive Mixed Effect Models (GAMMs) showed that inside the MPA increases in diversity metrics post-Storm were greater and more consistent over time than post-Bottom-Towed Fishing. As extreme events are likely to become more common with climate change, wave exposure observations indicated that 29\% of coastal reef MPAs around the United Kingdom may be exposed to comparable wave climate extremes, and may be similarly impacted. This paper therefore provides an insight into the likely extent and magnitude of ecological responses of seabed ecosystems to future extreme disturbance events.

Keywords: climate change, marine protected areas, temperate reef, storms, underwater video, benthic impact

\section{INTRODUCTION}

Marine protected areas (MPAs) have been established worldwide in an effort to limit direct anthropogenic drivers of ecosystem change (UNEP-WCMC and IUCN, 2016). To date, almost 17,000 MPAs have been designated within a wide range of ecoregions, covering $7.43 \%$ of the global ocean (UNEP-WCMC and IUCN, 2020). Anthropogenic influences on the marine environment are known to cause effects which are wide-ranging in scope and scale (Birchenough et al., 2015; 
GESAMP, 2018), especially bottom trawling (Fragkopoulou et al., 2021; Wang and Dudgeon, 2021), greatly exceeding natural rates and magnitudes of change (Barnosky et al., 2012). The value of MPAs goes beyond conserving existing biodiversity by removing some of the direct pressures on a system, potentially buffering against broad-scale state shifts (Graham et al., 2013) in response to natural disturbance. In doing so, MPAs have the potential to rewild and build resilience into the ecosystem by enhancing resistance, and/or recovery, preventing an ecosystem from shifting to an alternative state when subjected to disturbance (Angeler and Allen, 2016; Duarte et al., 2020).

While MPAs are aimed at managing direct anthropogenic disturbance on ecosystems at a local scale (ecosystem-based management), these same ecosystems are subject to changes in patterns of global environmental drivers, whose influences are likely to be exacerbated under projections of climate change. In the northeast Atlantic these projections include shifting patterns of extratropical cyclones, and an increase in the frequency of extreme storm events throughout the 21st century (Zappa et al., 2013; Lehmann et al., 2014). Furthermore, wave heights during extreme events have been observed to increase in recent decades (Young et al., 2011), therefore potentially increasing the impacts of each extreme event. With these anticipated shifts in wave forcing on coastlines and the seabed, it is important that the effects of extreme storm events on benthic assemblages are understood in order to inform long-term planning of conservation measures in the northeast Atlantic and beyond. In addition to gradual environmental change, discrete disturbance events are known to drive ecological change (Jentsch et al., 2007), by altering succession in tropical rain forests (Connell, 1978), coral reefs (Connell, 1978; Woodley et al., 1981), and macroalgae-dominated subtidal habitats (Cowen et al., 1982; Harris et al., 1984). However, while it is known that benthic community structure in coastal marine seabed ecosystems is driven in part by wave action (Connell et al., 1997), it is unclear whether the protection afforded by MPAs increases resilience of the benthos to stochastic high energy events. There are few studies focusing on storm disturbance in subtidal temperate reefs (Choat et al., 1988; Holbrook et al., 1994), likely due to a paucity of community composition data collected prior to the extreme events. Knowledge of the likely ecosystem responses to extreme storm events, and recovery timescales of impacted benthic habitats is key to ensure protection of sufficient habitat, species and genetic diversity to buffer against natural and anthropogenic disturbances, and provide a starting point for recovery.

Temperate reef systems perform vital roles in the cycling of nutrients, sequestration of carbon, and stabilisation of sediments, as well as supporting ecologically and economically important fish populations through provision of nursery, spawning, migration, and mating areas (Seitz et al., 2014). The productivity and resilience of these ecosystems is dependent on their ability to cope with environmental variability and direct anthropogenic disturbance (Barbier et al., 2011). Human disturbance in MPAs is often limited to discrete areas where defined habitat features, such as reef or seagrass have been mapped, leaving the majority of each MPA still vulnerable to disturbance. The alternative to this feature-based approach is to exclude destructive activities from the Whole Site (Rees et al., 2020; Solandt et al., 2020). This approach allows reef-associated species to colonise interreef sediments thereby rewilding the whole MPA, enhancing the functional reef and potentially stabilising sediments (Sheehan et al., 2013a). Lyme Bay MPA (southwest United Kingdom) was the first large scale MPA in the United Kingdom to adopt the Whole Site Approach, excluding bottom-towed fishing from $206 \mathrm{~km}^{2}$. The recovery of benthic communities was evident after 3 years (Sheehan et al., 2013b). However, after 5 years, an exceptionally stormy north Atlantic winter (2013-2014) hit the southwest of the United Kingdom (Kendon, 2015), and provided a unique opportunity to establish the magnitude of natural disturbance which can be caused by such extreme events. Here, we assess whether the Lyme Bay MPA enhanced the benthic ecological resilience to stochastic extreme disturbance relative to areas that remained open to bottom-towed fishing. Patterns of recovery from bottom-towed fishing or natural disturbance are also compared.

The aim of this study is to assess the impact of extreme storm events on benthic ecosystems, and to determine whether MPAs that exclude bottom-towed fishing confer resilience to their seabed assemblages. Here, resilience is considered as both the resistance of an ecosystem to shifting to an alternative state when subjected to a driver (Angeler and Allen, 2016), and/or the ability to recover from a disturbance to retain the same function and assemblage as the pre-disturbance state. This was achieved by assessing the response of temperate benthic assemblages to extreme storm conditions inside and outside of an MPA, using an 11-year ecological time series which incorporated both a period of extreme storm activity and previous recovery from the chronic impact of towed fishing gear. The wave climate of coastal MPAs around the United Kingdom was characterised in order to identify the scope of MPAs with similar or greater wave exposure that may be vulnerable to extreme storms events. Consequences for management and monitoring are also explored.

\section{METHODS}

\section{Site Description}

Lyme Bay, in the southwest of the United Kingdom (Figure 1), is home to a $206 \mathrm{~km}^{2}$ MPA from which bottom-towed fishing activities were excluded in July 2008 (The Lyme Bay Designated Area (Fishing Restrictions) Order, 2008, Statutory Instrument 2008/1584, under the Sea Fish (Conservation) Act 1967, 2008), while static fishing gear such as pots and nets continue to be permitted. Prior to this designation, four areas had been protected from bottom-towed fishing under voluntary agreements from 2001 covering $41 \mathrm{~km}^{2}$ by 2006 . Following the statutory designation, a broader area of Lyme Bay was designated as a Site of Community Importance in 2011, and finally a Special Area of Conservation (SAC) under the EU Habitats Directive, achieving SAC status in 2017 due to the presence of reefs and sea caves. From here on in, the "Lyme Bay MPA" specifically refers to the area designated in 2008, and doesn't include the wider boundaries of the SAC. The reef systems of Lyme Bay comprise 
low-lying outcrops of rock from the Lias Group, ${ }^{1}$ and a mosaic of pebbles, cobbles and boulders interspersed with coarse sediment (Sheehan et al., 2013b).

\section{Wave Power}

To evaluate the wave climate in MPAs nationally, and establish where Lyme Bay MPA resides within the range of wave exposure levels around the United Kingdom, wave buoy data were obtained from Datawell Directional Waverider Mk3 buoys operated around the United Kingdom by Channel Coastal Observatory. Wave parameters had been calculated by the Channel Coastal Observatory over $30 \mathrm{~min}$, based on a buoy sampling frequency of $3.84 \mathrm{~Hz}$, filtered and downsampled to $1.28 \mathrm{~Hz}$ prior to calculation. Further detail of data processing routines are available from the Channel Coastal Observatory (Channel Coastal Observatory, 2017). The wave parameters significant wave height (Hs) (m) and zero-crossing wave period $\left(\mathrm{T}_{\mathrm{z}}\right)(\mathrm{s})$, were cleaned using buoygenerated data quality flags. Subsequently, energy period $\left(\mathrm{T}_{\mathrm{e}}\right)(\mathrm{s})$ was calculated as $\mathrm{T}_{\mathrm{e}}=1.18 \mathrm{~T}_{\mathrm{z}}$, for calculation of wave power $(P)$ (kW per metre of wave front) (Cahill and Lewis, 2014), using Eq. 1 in the package R (R Core Team, 2019):

$$
P=\frac{\rho g^{2}}{64 \pi} H s^{2} T_{e}
$$

where $\rho$ is the density of seawater, $g$ is acceleration by gravity. Thus, $P$ incorporates wave height and period measurements in a single value, allowing for ease in the evaluation of the energy flux within a system, and facilitating comparisons between locations. In order to focus on high-energy waves within coastal reef MPAs, the 99th percentile wave power was calculated for all MPAs with a wave buoy within $10 \mathrm{~km}$, if the wave buoy and MPA had the same aspect with regard to prevailing waves. Geospatial data for MPA boundaries for all MPAs designated for the presence of Annex 1 reef features were obtained from the Joint Nature Conservation Committee (Joint Nature Conservation Committee, 2017). One wave buoy located at $50^{\circ} 41.600^{\prime} \mathrm{N}, 2^{\circ}$ $44.990^{\prime} \mathrm{W}$ is situated within $100 \mathrm{~m}$ of the eastern border of the study site, Lyme Bay MPA, and was used to provide an overview of the temporal variability of the wave climate to support the analysis of extreme storm impacts. Wave data for Lyme Bay MPA were considered first as a complete time series, to evaluate seasonal and interannual variability, and then as a subset of data specifically characterised as storm events. The storm threshold for West Bay is $4.03 \mathrm{~m}$ (Channel Coastal Observatory, 2017), so observations of significant wave height exceeding this value were included in the evaluation of storm events.

\section{Seabed Sampling}

The epibenthic and demersal community was monitored during the summer months annually between 2008 and 2018 using a towed underwater video system (TUVS), a non-destructive method which has been described in detail elsewhere (Sheehan et al., 2010, 2016). Briefly, a submersible video system with scaling lasers was used to collect video transects of approximately

\footnotetext{
${ }^{1}$ http://nora.nerc.ac.uk/id/eprint/17270/1/OR12032.pdf
}

$200 \mathrm{~m} \times 0.5 \mathrm{~m}$ at 51 sites within 17 areas which were visited each year (Figure 1). The sites represent two treatments, within MPA sites protected from bottom-towed demersal fishing activities, while static fishing gear types, predominantly creels and nets, continue to be used within the MPA. Outside of the MPA are sites which remain open to bottom-towed fishing (henceforth termed "Open"). For each Treatment, surveys were conducted in eleven (MPA) or six (Open) Areas, with each Area comprising three replicate Sites. Site were selected based on their historic fishing effort, benthic substrate type and depth, with all sites located on hard or mixed substrates (rock, boulders, or cobbles) and consistent water depths between treatments (median depths of 22 and $24 \mathrm{~m}$ for MPA and Open sites, respectively) (Sheehan et al., 2013a; Stevens et al., 2014; Davies et al., 2021).

\section{Video Data Extraction and Analysis}

Video footage collected over the eleven surveys between 2008 and 2018 were analysed according to a standard procedure comprising two main approaches. Firstly, mobile and infrequent fauna were enumerated by viewing each video transect at full speed, counting individuals passing between the scaling lasers. Secondly, frames were extracted from transect footage at 5-s intervals using bespoke software (Cybertronix CXOverlay), and subsampled in order to obtain 30 frames for quantification of sessile and sedentary fauna (Sheehan et al., 2013b), which were then averaged at the Transect level. Organisms were identified to the lowest taxonomic level possible. Where taxonomic identification was not possible, species were grouped into morpho-taxa levels. The spatial extent of each frame was calculated from the position of the lasers on-screen, thereby allowing the density of taxa to be calculated. Data from video and frames analyses were combined for statistical analysis.

From the video data analysis, the response metrics number of taxa, abundance, and assemblage composition were calculated in order to examine broad patterns over time for each treatment and between treatments, and to test whether the storms of 20132014 affected epibenthic assemblages. Finally, the assemblage composition was used to determine whether the MPA enhanced resilience through facilitating a return to a similar assemblage as the pre-storm state in the years following the storm disturbance.

\section{Ecological Data Analysis}

To assess change in diversity, univariate response metrics, taxon density and abundance, were assessed over time and over time since impact across both treatments. These univariate response metrics were analysed using General Additive Mixed Effects Models (GAMMs) from the "mgcv" package within the programming language r (Wood, 2017; R Core Team, 2021). Both response metrics were assessed using a Gamma distribution with a "loglink" as they are both non-negative continuous values. Primarily, response metrics were assessed as a function of Year (2008-2018) and Treatment (MPA and Open) with Depth (four levels: 15, 20, 25, and $30 \mathrm{~m}$ ) and Area (1-17) as random factors. Response metrics were then assessed as a function of Years Since Impact (0-4), Treatment (MPA and Open) and Period (postBottom-Towed Fishing: 2008-2012 and post-Storm: 2014-2018) 


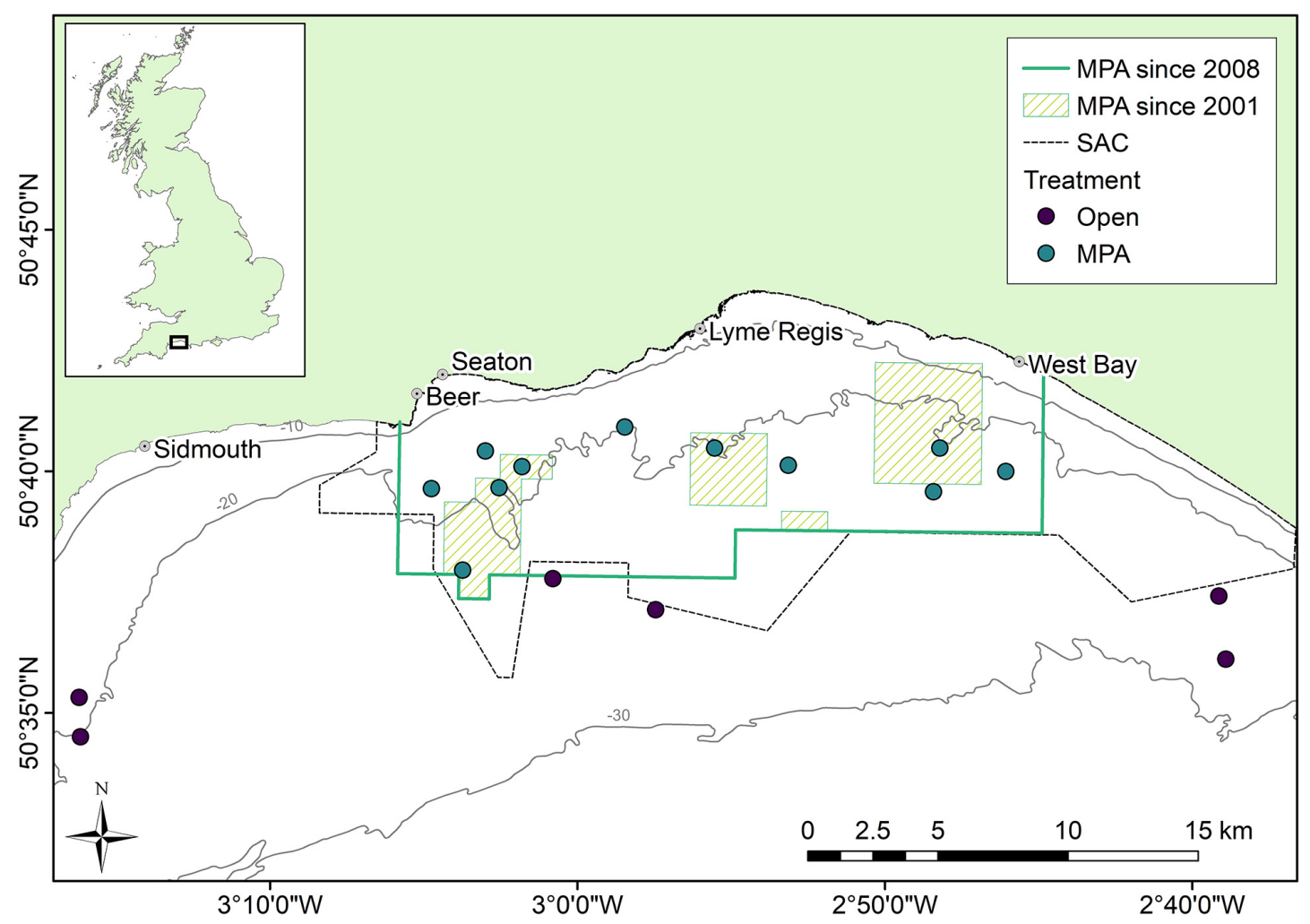

FIGURE 1 | Survey location in Lyme Bay, southwest United Kingdom. Points indicate the area centroid of three replicate towed video 200 m transects.

with Depth (four levels: 15, 20, 25, and $30 \mathrm{~m}$ ) and Area (117) as random factors. A thin plate penalized regression spline was applied to the Year effect within each level of Treatment for the first analysis and Years Since Impact effect within each level of Period for the second analysis to allow for a nonlinear relationships to be assessed (Wood, 2003), the number of basis functions included within these smoothers was determined using the GCV (Wood, 2004). Model selection was carried out using stepwise deletion of terms and pairwise comparisons of models by AIC. The most parsimonious models were applied using a restricted maximum likelihood and the highest order interactions evaluated. Sample vs. fitted residuals, quartilequartile and autocorrelation of temporally sequential samples were assessed visually, to fit assumptions of the models used.

Permutational multivariate analysis of variance (PERMANOVA+ in the PRIMER v7 software package (Anderson, 2001)) was used to test whether the epibenthic assemblage was significantly different between treatments over time. Three factors were used to examine differences between treatments: Year (fixed; 2008-2018), Treatment (fixed; MPA, Open), and Area (random; nested in Treatment, 1-17) with three replicate Sites per Area (random; nested in Area and Treatment). Assemblage composition was based on Bray Curtis similarity of dispersion weighted and fourth root transformed data to downweight dominant and highly clustered taxa (Bray and Curtis, 1957; Clarke et al., 2006). Significant differences between Treatment, or an interaction of Year and Treatment, in univariate metrics were further explored with pairwise tests while, for multivariate data, similarity percentage routines (SIMPER) were conducted to identify influential species driving differences in Assemblage composition (Clarke and Warwick, 2001). For SIMPER analysis, time periods were grouped and defined based on similarities between ecological patterns between years as determined from inspection of the nMDS visualisation of assemblage composition. Further detail was derived from the Assemblage data by focusing on pre-selected indicator species representing a suite of life history characteristics (Jackson et al., 2008).

\section{RESULTS}

\section{Wave Energy Characterisation}

Wave data were available for 38 MPAs nationally, of a total of 106 coastal MPAs containing reef features. Of those MPAs for which wave data were available, 8 (23\%) exhibited 99th percentile wave power values greater than that of Lyme Bay MPA (Figure 2).

Observations of the wave climate within Lyme Bay over the period 2008-2018 indicate that while seasonal and interannual variation are considerable (Figure 3A), the 2013-2014 winter season represents the most energetic period within the instrumental record for Lyme Bay. This is supported by observations of wave power $(P)$ distributions for all records exceeding the $4.03 \mathrm{~m}$ storm threshold. The median $P$ of 


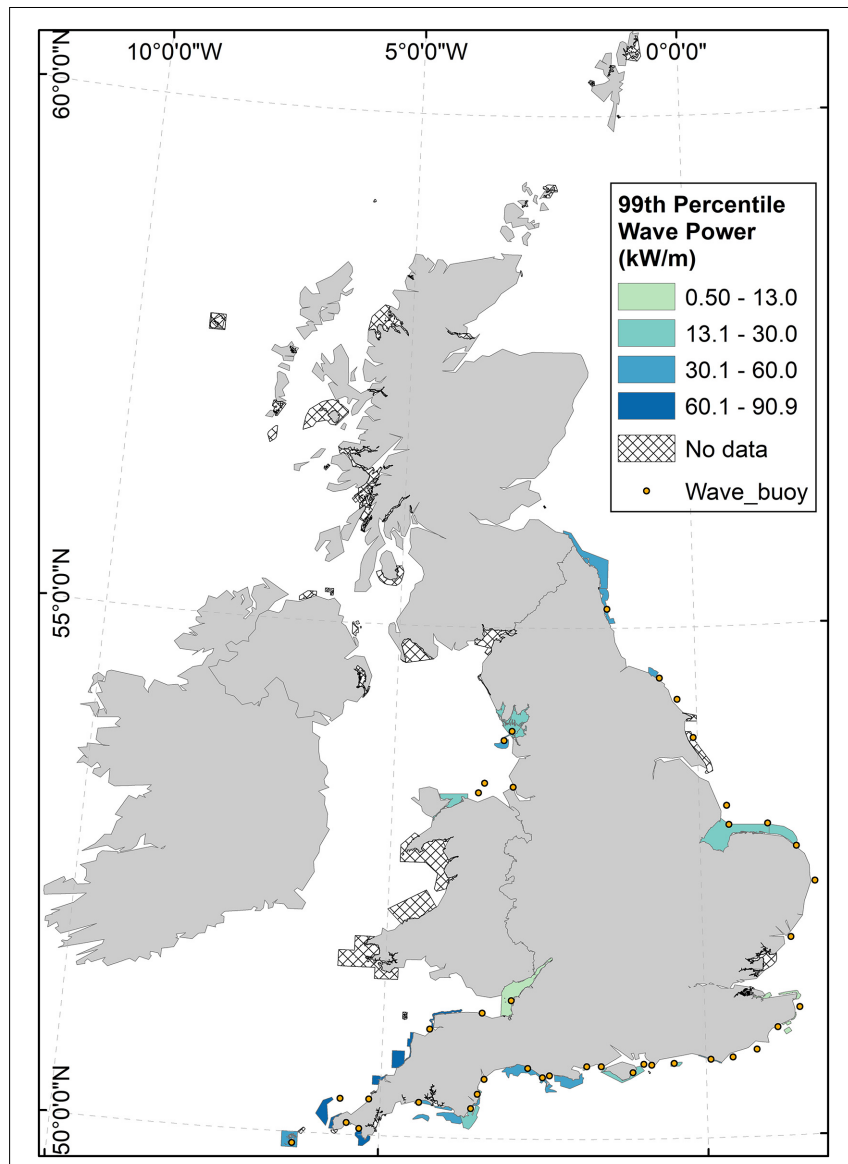

FIGURE 2 | Wave power in coastal reef MPAs around the United Kingdom (coloured polygons), and wave buoy distribution around the United Kingdom (dots). Wave power was calculated according to Eq. 1, using wave buoy data from buoys $<10 \mathrm{~km}$ from the MPA, and with the same aspect to prevailing waves. Hatched MPA polygons indicate a lack of available wave data.

observations exceeding the storm threshold in the 2013-2014 season $\left(85.8 \mathrm{~kW} \mathrm{~m}^{-1}\right)$ is lower than that of the 2015-2016 and 2016-2017 seasons (88.9 and $108 \mathrm{~kW} \mathrm{~m}^{-1}$, respectively) (Figure 3B). However, focusing on extreme events, the 95th percentile storm wave power of $2013-2014$ is $191 \mathrm{~kW} \mathrm{~m}^{-1}$, exceeding the 2015-2016 and 2016-2017 winter season by approximately 35 and 25\%, respectively. Furthermore, the 20132014 season represents $39.7 \%$ of all observations exceeding the storm threshold over the 11-year record, with 2015-2016 and 2016-2017 representing 15 and $2 \%$ of observations over the same period, respectively.

\section{Preliminary Observations}

On first assessment, the effects of the storms appeared to devastate the MPA. Loose unconsolidated sediments were prolific where biogenic crusts had been observed the year before. There was a lack of brittle species such as ross coral Pentapora foliacea, and evidence of sand scour on empty, clean king scallops Pecten maximus and at the base of pink sea fans Eunicella verrucosa.
By 2016, large numbers of juvenile E. verrucosa were observed surrounding apparently healthy-looking adults (see Figure 4).

\section{Ecosystem Response - Univariate Metrics}

Focusing on the univariate metrics, number of taxa and overall abundance, some obvious patterns were evident. Overall, the MPA broadly supported a greater number of taxa (Table 1 $p<<0.0001$; Figure 5A) and overall abundance of individuals (Table $1 p<<0.0001$; Figure 5B) than the Open treatment over the course of the monitoring period (Table 1).

When post-Bottom-Towed Fishing and post-Storm periods were assessed, the number of taxa and the overall abundance showed increases with years since impact in the MPA regardless of time period (Figure 6 and Table 2: s(Since):Storm and s(Since):Bottom-Towed Fishing $p<<0.0001)$. The MPA was consistently greater in the number of taxa and overall abundance than the Open, with a greater and more consistent difference post-Storm than post-Bottom-Towed Fishing (Figure 6 and Table 2: Period $\times$ Treatment $p=0.027$ and $p=0.025$ for number of taxa and overall abundance, respectively). The number of taxa and the overall abundance observed in the MPA remained relatively stable for the first 3 years following designation as an MPA, a pattern which is not evident in the first 3 years following the storms of 2013/2014, where an immediate increase in both response metrics was evident between 2014 and 2017 (Figures 5, 6). In contrast, the Open treatment exhibits a similar pattern of variability following the storm period as in the rest of the time series (Figures 5, 6).

Between 2008 and 2013, the mean number of taxa $\pm 95 \%$ $\mathrm{CI}$ in the MPA increased by $105 \%$, from $0.251 \pm 0.018$ to $0.514 \pm 0.063$ taxa $\mathrm{m}^{-2}$, while in the Open treatment over the same period, an increase of $26.8 \%$, from $0.192 \pm 0.028$ to $0.244 \pm 0.048$ taxa $\mathrm{m}^{-2}$ was observed. Concurrently, overall abundance increased by $64.9 \%$, from $19.8 \pm 1.67$ to $32.7 \pm 2.09$ individuals $\mathrm{m}^{-2}$ in the MPA, and $26.2 \%$, from $14.5 \pm 2.34$ to $18.2 \pm 2.07$ individuals $\mathrm{m}^{-2}$ in the Open treatment.

Following the initial phase of recovery, the 2013/2014 storms impacted the number of taxa within the MPA treatment, while in the Open treatment, there was some evidence of storm damage, but changes remained within the typical interannual variability of this treatment (Figure 5A). Between the summers 2013 and 2014, the number of taxa in the MPA and Open treatments decreased by $52.3 \%$ in the MPA and $13.4 \%$ in the Open treatment, falling to 97.8 and $110 \%$ of 2008 levels, respectively $\left(0.245 \pm 0.024\right.$ and $0.212 \pm 0.033$ taxa $\left.\mathrm{m}^{-2}\right)$. Overall abundance was impacted in the MPA and in Open sites, reducing mean overall abundance to 90.3 and $87.4 \%$ of 2008 levels for MPA and Open treatments, respectively (down to $17.9 \pm 1.38$ and $12.6 \pm 1.11$ individuals $\mathrm{m}^{-2}$ ). By 2018 , the mean number of taxa in the MPA was $0.392 \pm 0.042$ taxa $\mathrm{m}^{-2}, 56.3 \%$ greater than 2008 levels, while in the Open treatment $0.240 \pm 0.029$ taxa $^{-2}$ were observed, representing an increase of $24.6 \%$ over the same period. Overall abundance between 2008 and 2018 increased by $35.3 \%$ to $26.8 \pm 3.03$ individuals $\mathrm{m}^{-2}$ in the MPA and by $0.95 \%$ to $14.6 \pm 1.33$ individuals $\mathrm{m}^{-2}$ in Open sites. Between 2014 

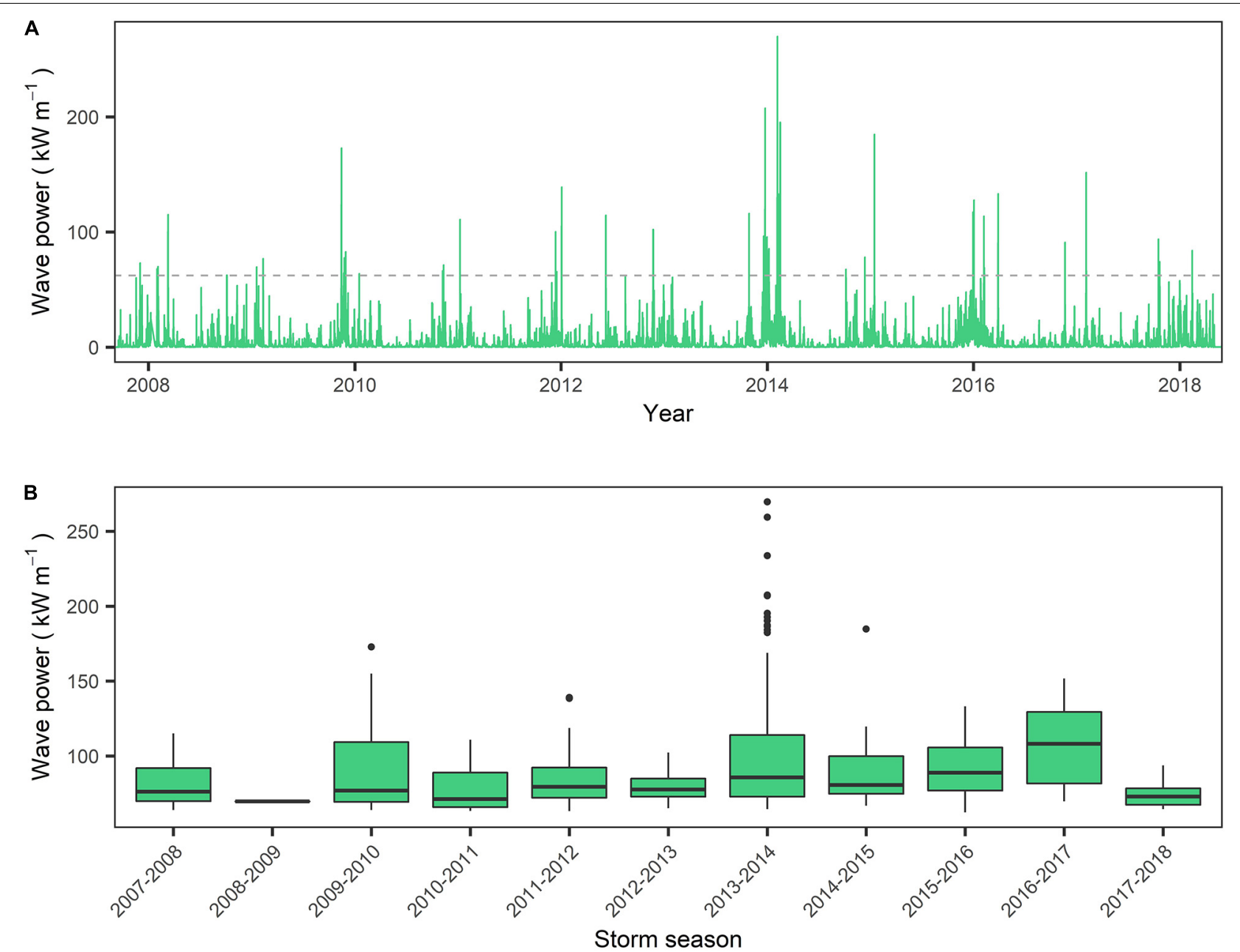

FIGURE 3 | (A) Wave power for the period September 2008-June 2018, calculated from wave data gathered by the West Bay wave buoy on the eastern border of Lyme Bay MPA. Dashed line represents the wave power consistent with the storm threshold of $4.03 \mathrm{~m}$; (B) Wave power within each storm season

(September-September) for all records exceeding storm threshold of $4.03 \mathrm{~m}$ significant wave height.

and 2018 , the number of taxa increased by 59.9 and $13.4 \%$ in MPA and Open treatments, respectively. Over the same period, overall abundance increased by 49.9 and $15.5 \%$ in MPA and Open treatments.

\section{Ecosystem Response - Multivariate Metrics}

The Assemblage composition of the MPA remained similar for 2 years following cessation of bottom-towed fishing within the MPA (Figure 7 and Table 3), before shifting in 2011, concurrent with the increase in diversity and abundance observed in univariate indices. Despite observed similarities in univariate metrics between treatments in the number of taxa and overall abundance in 2009, the Assemblage composition remained distinct between MPA and Open. In the first year after the extreme storms (2014), both treatments exhibited considerable change compared to 2013, with the assemblage in the MPA shifting back towards an earlier state, and becoming more similar to the Open treatment. In the Open treatment, the assemblage also shifted considerably, becoming less similar to all previous observations.

The component of variation estimate calculated in a PERMANOVA routine is considered as the multivariate effect size between treatments and indicates that there was a gradual divergence in assemblage composition between treatments over the first 4 years, with the exception of 2012 (Table 4). A new peak was reached in 2013 before the extreme storm events. As a result of the extreme storm events in the winter of 2013/2014, assemblages became more similar between treatments, but subsequently diverged again, and by 2017 the assemblages had become less similar than they had been at any point in the previous 9 years.

To further evaluate the species driving differences between treatments, similarity percentages (SIMPER) were evaluated using time periods determined from visual inspection of the nMDS plot (Figure 7), resulting in four broad time periods - namely, Early (2008-2010), Peak (2011-2013), Storm (2014), and Recovery (2016-2018). The SIMPER 


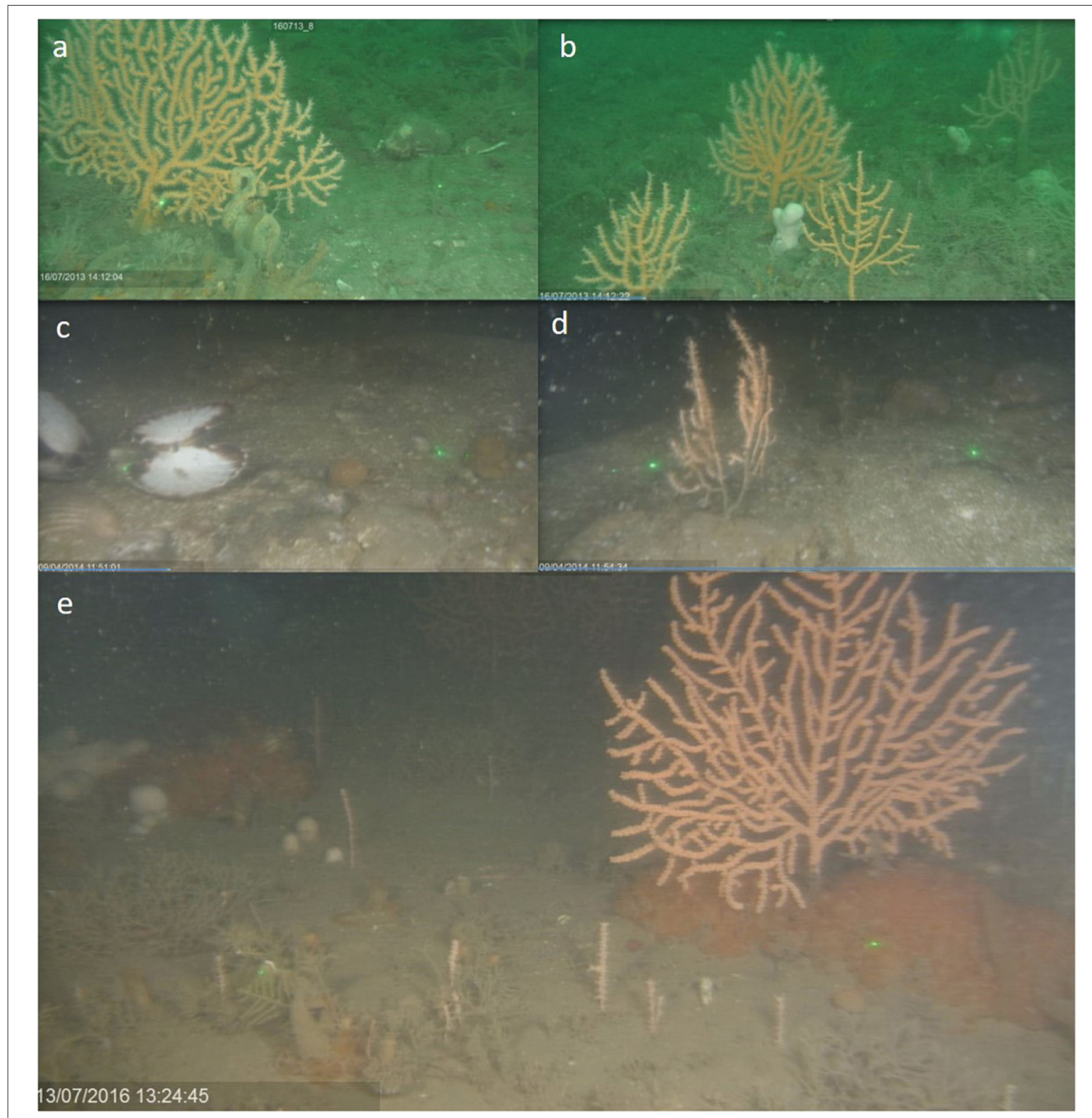

FIGURE 4 | Images from Site 56, in the south east corner of the MPA. (a,b) 2013, after 5 years protection from bottom-towed fishing, prior to extreme storms. (c,d) After extreme storms in 2014. Influx of sediment apparent with evidence of sand scour on e.g., scallops and pink sea fans. (e) 2 years after extreme storms in 2016 with evidence of recovery of adult pink sea fans with high levels of juvenile recruits.

analysis highlighted a number of species consistently driving differences between treatments; for example, aside from the early period immediately following protection, branching sponges were consistently elevated in the MPA in comparison to Open sites (Supplementary Table 1). However, other species (e.g., P. foliacea), potentially more susceptible to physical damage, drive differences between treatments in the Early and Peak periods, but were not sufficiently abundant in the Storm or Recovery period to contribute to the differences between treatments. Furthermore, some species contributing to differences between treatments were elevated in the Open controls, compared with the MPA. Species such as Callionymus lyra and Pagurus spp. tended to be more abundant in the Open controls. Of interest are those species which appear to become 
TABLE 1 | Model Outputs for General Additive Mixed Effects Models (GAMMs) using a Gamma distribution to model the number of taxa and overall abundance as a function of Year and Treatment with Depth and Area as random factors.

\begin{tabular}{|c|c|c|c|c|c|}
\hline Metric & Parameter & Coefficient & SE & $t / F$ Value & $p$ value \\
\hline \multirow[t]{4}{*}{ Taxa } & (Intercept) & -1.062 & 0.036 & -29.733 & $<0.0001^{\star * *}$ \\
\hline & Treatment & -0.411 & 0.060 & -6.862 & $<0.0001^{\star * *}$ \\
\hline & s(Year):MPA & & & 24.188 & $<0.0001^{\star \star \star}$ \\
\hline & s(Year):Open & & & 4.096 & $<0.0001^{\star \star * *}$ \\
\hline \multirow[t]{4}{*}{ Abundance } & (Intercept) & 3.151 & 0.037 & 84.427 & $<0.0001^{\star \star *}$ \\
\hline & Treatment & -0.478 & 0.062 & -7.749 & $<0.0001^{\star * *}$ \\
\hline & s(Year):MPA & & & 17.916 & $<0.0001^{\star * *}$ \\
\hline & s(Year):Open & & & 2.614 & 0.18 \\
\hline
\end{tabular}

$s$ denotes a thin plate regression spline.

Bold $p$ values denote significant effects ( $\alpha=0.05$ ).

${ }^{*} p<0.05,{ }^{* *} p<0.005,{ }^{* * *} p<0.0005$.

major contributors to differences between treatments in the Storm period. Species such as Ophiura ophiura and Pagurus spp. exhibit strong responses to the storm events, becoming more abundant in the Open controls, compared to the MPA.

Of the species contributing the most to differences between treatments, some belong to a group of indicator taxa selected a priori (Jackson et al., 2008) when the monitoring of Lyme Bay MPA was initiated in 2008. A range of responses to protection and storm disturbance were observed over the time series, and it is informative to consider the patterns occurring in the MPA established in 2008, alongside subregions within it which have been offered voluntary protection since 2001. These data are presented separately in Figure 8. Long-lived species such as Alcyonium digitatum, Branching sponges and $P$. foliacea responded slowly to the designation of the MPA in 2008, and were shown to be vulnerable to storm damage (Figure 8). However, A. digitatum and P. foliacea exhibited limited recovery following the storms, whereas Branching sponges rapidly returned to their pre-storm levels. Other longlived indicator taxa (e.g., E. verrucosa, Tethya aurantium) exhibited smaller declines in abundance following the storms, and increased in abundance considerably in the years which followed (Figure 8). More ephemeral taxa such as Phallusia mammillata and Hydroids exhibited a considerable degree of variability, but both were impacted by the storm period (Figure 8). P. maximus is a commercially exploited bivalve species in Lyme Bay which exhibited considerable interannual variability, peaking in abundance within the MPA in 2011 and reaching a minimum in 2015 , one year later than the minimum in most indicator species. Following this minimum, P. maximus remained in low abundance within the MPA. In Open sites, $P$. maximus exhibited a steady decline in abundance between 2008 and 2012, and subsequently remained at this level.

\section{DISCUSSION}

Using 11 years of observations of benthic ecology inside Lyme Bay MPA and in nearby Open controls, a marked effect of extreme storms on the benthos in a temperate reef system was detected. Despite a considerable degree of variability in responses between taxa (Figures 7, 8), the storms of 20132014 returned benthic diversity inside the MPA to pre-protection levels (Figures 5A, 6A). Recovery from the storms inside the MPA was more rapid than recovery from bottom-towed fishing, while the benthos in Open controls remained in an impacted state throughout the time series. Ecological resilience consists of elements of resistance and recovery (Angeler and Allen, 2016), and these observations suggest Lyme Bay MPA is conferring resilience through enhanced recovery despite offering little in terms of resistance to extreme storms. Among coastal MPAs in the United Kingdom which are designated for the presence of Annex-1 reef habitats a broad range of wave power estimates are evident. In terms of wave power, Lyme Bay could be considered as a moderately exposed MPA. Approximately 23\% of MPAs for which wave buoy data were available exhibit winter wave power values exceeding those of Lyme Bay MPA (Figure 2). While the removal of bottom-towed fishing certainly aided a rewilding process to occur inside the MPA, the surrounding area is still open to those activities that maintain loose unconsolidated sediments. While MPAs are surrounded by such sediments they should still be considered vulnerable to the effects of severe sand scour driven by extreme storm events. Consequently, it is likely that many other temperate reef systems within MPAs undergo natural shifts in abundance and diversity driven by extreme storm events (Figure 2).

\section{Effects of Disturbance}

Owing to the greater diversity, and greater sensitivity of species present in the MPA immediately prior to the storm period, the effects of the storms in terms of species and individuals lost were greater within the MPA than in Open controls. This has recently been recognised as the protection paradox (Bates et al., 2019), whereby elevated populations and sensitivity of assemblages in MPAs causes reduced resilience to disturbance events. However, subsequent increases in the number of taxa and overall abundance, and consistency of assemblage composition within the MPA, indicate that once aspects of recovery are considered, Lyme Bay MPA represents a more resilient system. The elevated rate of recovery from storm disturbance within the MPA following a period of protection from direct physical disturbance suggests that, while MPAs may not protect ecosystems from 

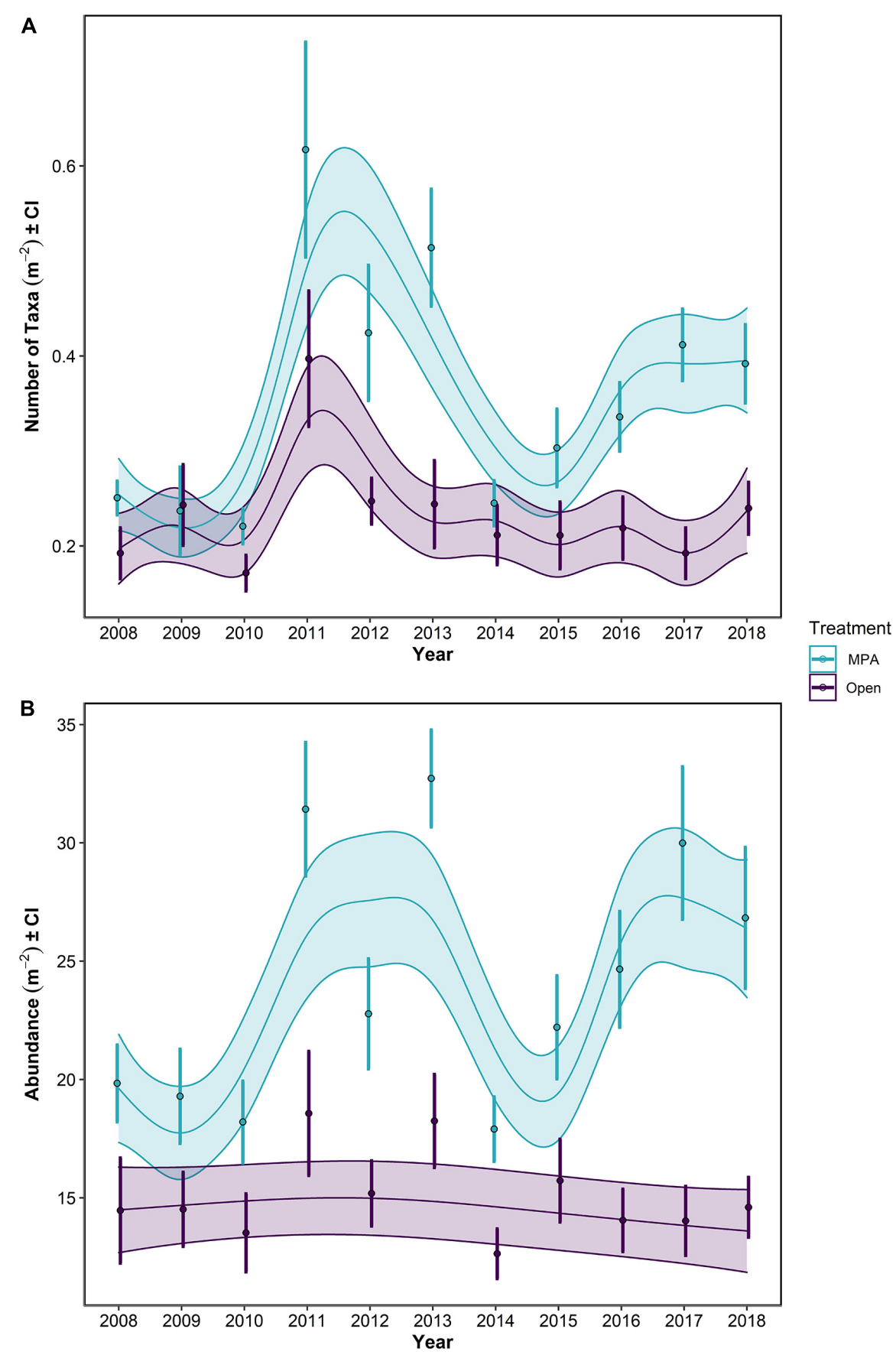

FIGURE 5 | (A) Number of taxa and (B) Abundance for the period 2008-2018 in the Lyme Bay marine protected area (MPA; blue) and Open control treatments (Open; purple). Lines show GAMMs estimates with shading showing 95\% Confidence Intervals. Points with errors bars show mean values and 95\% Confidence Interval.

stochastic extreme conditions, they can enhance the recovery, therefore resilience in the system.

During two recovery periods, from 2008 to 2010, and from 2014 to 2016, the slower initial rate of increase in the number of taxa, compared to overall abundance, suggests a pattern of increases in existing populations prior to a period of colonisation by additional species. However, the dominant species in these treatments remain consistent, with changes of assemblage within treatments being driven by species of lower abundance locally (Figure 6). Such patterns of recolonisation are to be expected where patches of disturbed habitat are interspersed with patches exhibiting lesser degrees of impact, allowing recolonisation from local populations or processes of vegetative growth (Connell and Keough, 1985). 

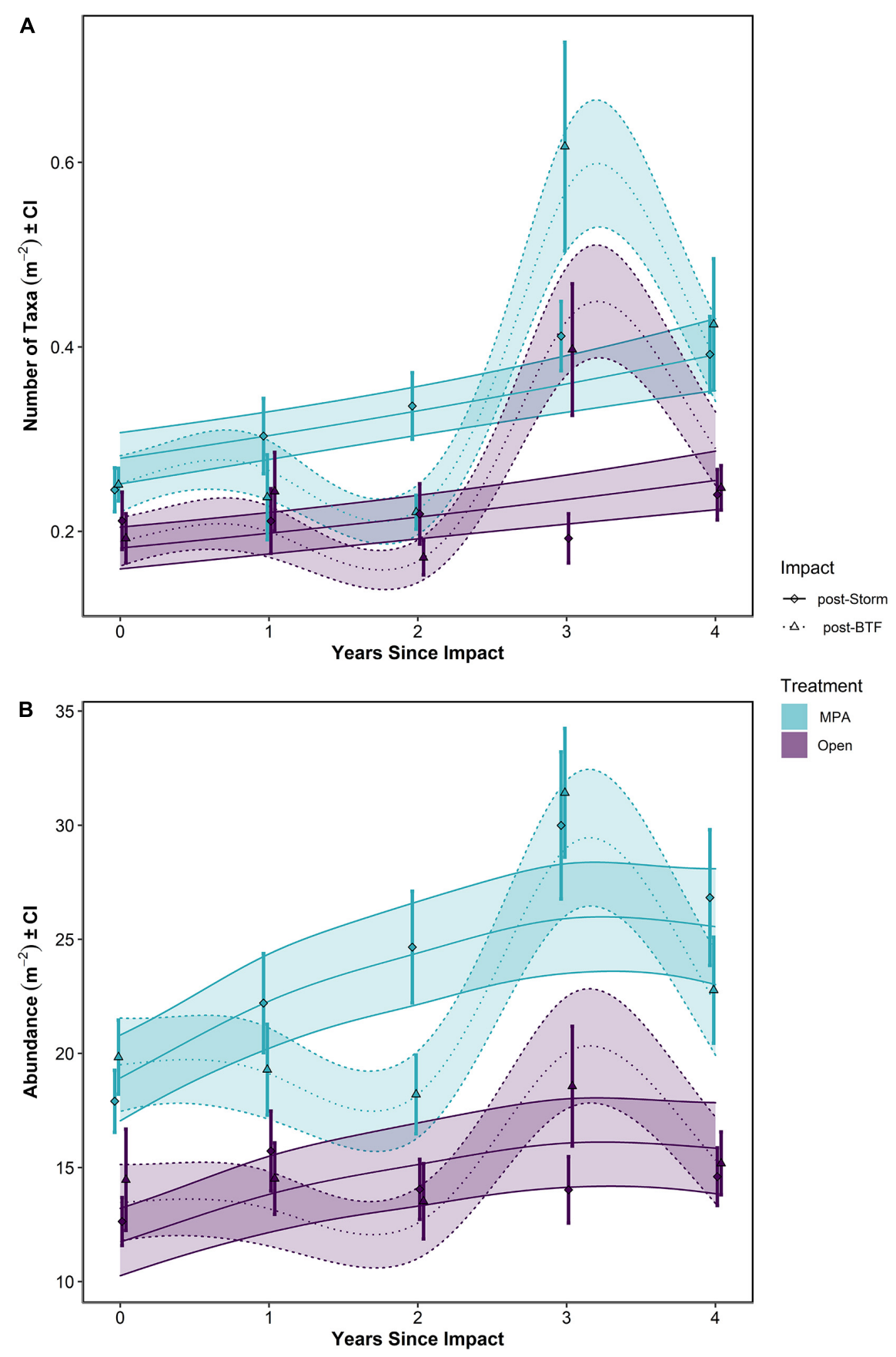

\section{Treatment

FIGURE 6 | (A) Number of taxa and (B) Abundance over Years Since Impact in the Lyme Bay marine protected area (MPA; blue) and Open control treatments (Open; purple), and post-Bottom-Towed Fishing (dashed lines and triangles) and post-Storm (solid lines and diamonds). Lines show GAMMs estimates with shading showing 95\% Confidence Intervals. Points with errors bars show mean values and 95\% Confidence Interval. Bottom-Towed Fishing is abbreviated to BTF.

\section{Drivers of Change}

The observed effects of storm disturbance are likely to have been caused by a combination of direct hydrodynamic forces and sediment dynamics. The benthic habitat of Lyme Bay comprises rocky reef, boulders and coarse sediment, and as such supports a diverse assemblage of reef-associated species. However, the response of these different habitat types to storm disturbance will vary, with bedrock reef features being susceptible to scour or smothering, while boulders and coarse sediments will be prone to movement and overturning. Sediment movement during storm events is known to cause damage to organisms due to scouring (Woodley et al., 1981), while redistribution of sediment may present challenges to organisms through smothering or the increased energetic costs of living under high suspended 
TABLE 2 | Model Outputs for General Additive Mixed Effects Models (GAMMs) using a Gamma distribution to model the number of taxa and overall abundance as function of Years Since Impact, Treatment and Period with Depth and Area as random factors.

\begin{tabular}{|c|c|c|c|c|c|}
\hline Metric & Parameter & Coefficient & SE & $t / F$ Value & $p$ value \\
\hline \multirow{4}{*}{ Taxa } & Period & -0.031 & 0.038 & -0.823 & 0.41 \\
\hline & Period $\times$ Treatment & 0.141 & 0.064 & 2.215 & $0.027^{\star}$ \\
\hline & $\mathrm{s}($ Since):Storm & & & 32.761 & $<0.0001^{\star * *}$ \\
\hline & s(Since):BTF & & & 67.852 & $<0.0001^{\star * *}$ \\
\hline & Period & -0.087 & 0.027 & -3.239 & $0.0013^{\star \star}$ \\
\hline & Treatment & -0.478 & 0.070 & -6.797 & $<0.0001^{\star * *}$ \\
\hline & Period $\times$ Treatment & 0.107 & 0.048 & 2.252 & $0.025^{\star}$ \\
\hline & $\mathrm{s}($ Since):Storm & & & 24.856 & $<0.0001^{\star * *}$ \\
\hline & s(Since):BTF & & & 26.989 & $<0.0001^{\star \star \star}$ \\
\hline
\end{tabular}

$s$ denotes a thin plate regression spline.

Bold $p$ values denote significant effects $(\alpha=0.05)$.

Bottom-Towed Fishing is abbreviated to BTF.

${ }^{*} p<0.05,{ }^{* *} p<0.005,{ }^{* *} p<0.0005$.

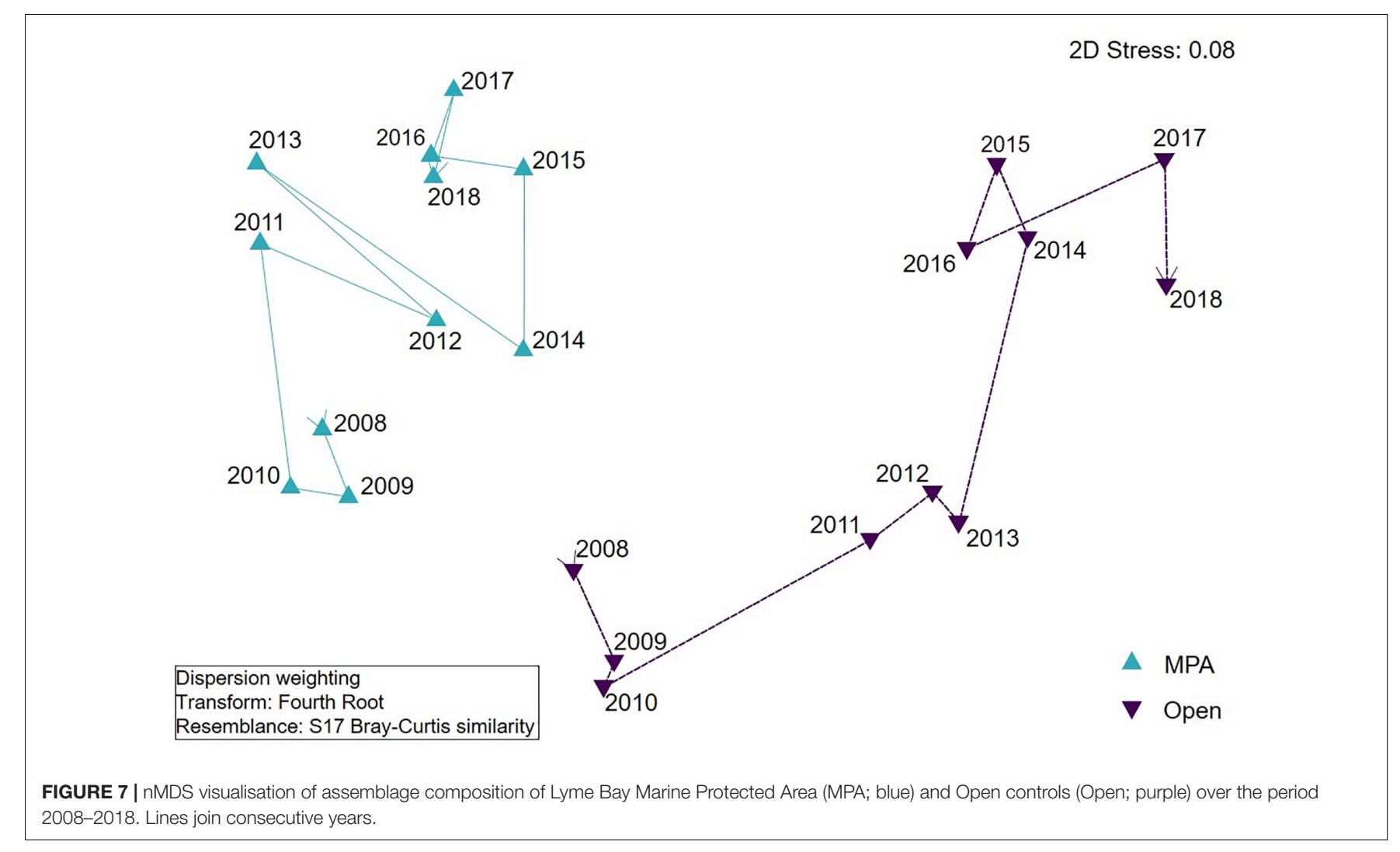

particulate loads (Szostek et al., 2013). While it was not possible to evaluate this in the present study, distance to the nearest sandy area may be of importance in the effects of storm disturbance on reef-associated species. Overturning of cobbles can also remove sessile species (Scheibling et al., 2009) and alter rocky sub-tidal habitats with significant effects on reef community structure (Posey et al., 1996; Renaud et al., 1997). Some species such as encrusting organisms are likely to be less susceptible to damage than branching or massive forms (Posey et al., 1996;
Vaselli et al., 2008), and the loss of these structure-building taxa is likely to have wider effects owing to their importance in settlement and recruitment of other species of ecological and economic importance (Bradshaw et al., 2003). Sediments can be stabilised by the presence of epibenthic organisms (Bradshaw et al., 2003), and it may be that an older MPA with more well-established epifaunal populations could be more resistant to the impact of sediment dynamics in the event of extreme storm events. However, protection afforded through sediment 
TABLE 3 | Summary results of PERMANOVA analyses of the number of taxa, overall abundance, and assemblage composition for the fixed factors Year and Treatment and their interaction, and Area (random, nested in Treatment).

\begin{tabular}{|c|c|c|c|c|c|c|c|}
\hline Metric & Source & df & ss & MS & Pseudo-F & $\mathbf{P}($ perm $)$ & Unique perms \\
\hline Assemblage & Year & 10 & 183880 & 18388 & 12.167 & 0.0001 & 9796 \\
\hline \multirow[t]{6}{*}{ composition } & Treatment & 1 & 131510 & 131510 & 14.415 & 0.0001 & 9933 \\
\hline & Area(Treatment) & 15 & 134950 & 8996.4 & 11.92 & 0.0001 & 9741 \\
\hline & Year $\times$ Treatment & 10 & 42482 & 4248.2 & 2.8071 & 0.0001 & 9742 \\
\hline & Year × Area(Treatment) & 150 & 223810 & 1492.1 & 1.977 & 0.0001 & 9273 \\
\hline & Residual & 358 & 270190 & 754.73 & & & \\
\hline & Total & 544 & 986820 & & & & \\
\hline
\end{tabular}

Taxa data were not transformed, Abundance and Assemblage Composition data were dispersion weighted and fourth root transformed.

stabilisation requires the whole-site approach, since unprotected habitats between protected features can remain susceptible to disturbance, inhibiting the development of sediment-stabilising benthic fauna (Sheehan et al., 2013a). Through restricting direct human impacts on benthic assemblages, and thereby increasing sediment stability, MPAs which employ the whole-site approach to management serve a purpose in mitigating some of the effects of extreme storm events. However, organisms within MPAs would still be subject to hydrodynamic forces or the movement of sediment influxes from outside of the MPA.

With projected increases in the frequency of extreme storms in the northeast Atlantic (Zappa et al., 2013; Lehmann et al., 2014), rapid recovery rates are needed to safeguard ecosystems against progressive deterioration and regime shifts. Inter-annual variability of storm activity is much greater than that of tidally driven currents on the United Kingdom continental shelf (Bricheno et al., 2015), so it is likely that infrequent extreme storm events will have a greater impact on colonisation and succession in the benthic community than tidal currents. This work provides an example of the mechanisms which may drive resilience patterns. However, responses were highly variable between taxa, and likely driven by the life history or growth strategies of species. Some species appeared to benefit from the effects of storm disturbance (e.g., Pagurus spp.), perhaps owing to their diverse feeding methods (Gerlach et al., 1976) and increased food availability following storm disturbance, while other, more fragile or long-lived species (e.g., P. foliacea) were heavily impacted by the storms, and exhibited a very slow rate of increase in abundance in the years that followed. Each of these species' responses led to an overall shift in assemblage composition in both treatments in 2014, but while the MPA appears to be returning to a state similar to its pre-storm condition (Figure 7), the Open controls have remained in their changed state. Therefore it should be considered that the MPA is exhibiting a greater degree of resilience than the Open treatment (Holling, 1973); while the MPA was less able to resist the effects of storms, it was more capable of returning to a similar state in the years which followed (Figure 7). This can be seen as a tendency for the assemblage to return in the direction of the pre-storm (2013) state (shown as a shift to the left from 2015), while assemblages in the Open treatment remained divergent from 2013 to 2018 (shown as a shift downward in 2018).

\section{Monitoring Recommendations}

The natural variability of benthic communities inside and outside of MPAs must be monitored to evaluate whether an MPA is successful in attaining the original conservation goals, identify where management or stakeholder efforts might benefit from refinement, and inform management decisions (Rees et al., 2020). Within Europe, current management strategies look to achieve Good Environmental Status, as required by the European Marine Strategy Framework Directive (European Commission, 2008), but approaches to management rely on comparisons of the state of the environment at regular intervals with a baseline generated on an ad-hoc basis when evidence is required for designation of a particular MPA. The variability exhibited within Lyme Bay MPA has highlighted the need to consider the potential biodiversity or carrying capacity of a system, rather than its state at a single time point when setting conservation objectives. To ensure appropriate conclusion are drawn, the effects of disturbance events of all types (storms, heatwaves, and hypoxic events) should be factored into ecological monitoring programmes, and caution should be exercised when using post-disturbance observations to evaluate the state of a system (Bicknell et al., 2019). In the United Kingdom, for example, SACs are required to be monitored every 6 years. The Lyme Bay long-term monitoring data has demonstrated that during this timescale, recovery

TABLE 4 | Multivariate effect size between treatments MPA and Open, as Component of Variation Estimate.

\begin{tabular}{lc}
\hline Year & Effect size \\
\hline 2008 & 216.96 \\
2009 & 253.67 \\
2010 & 382.62 \\
2011 & 724.71 \\
2012 & 484.28 \\
2013 & 870.40 \\
2014 & 528.84 \\
2015 & 437.65 \\
2016 & 655.11 \\
2017 & 899.98 \\
2018 & 1017.9
\end{tabular}




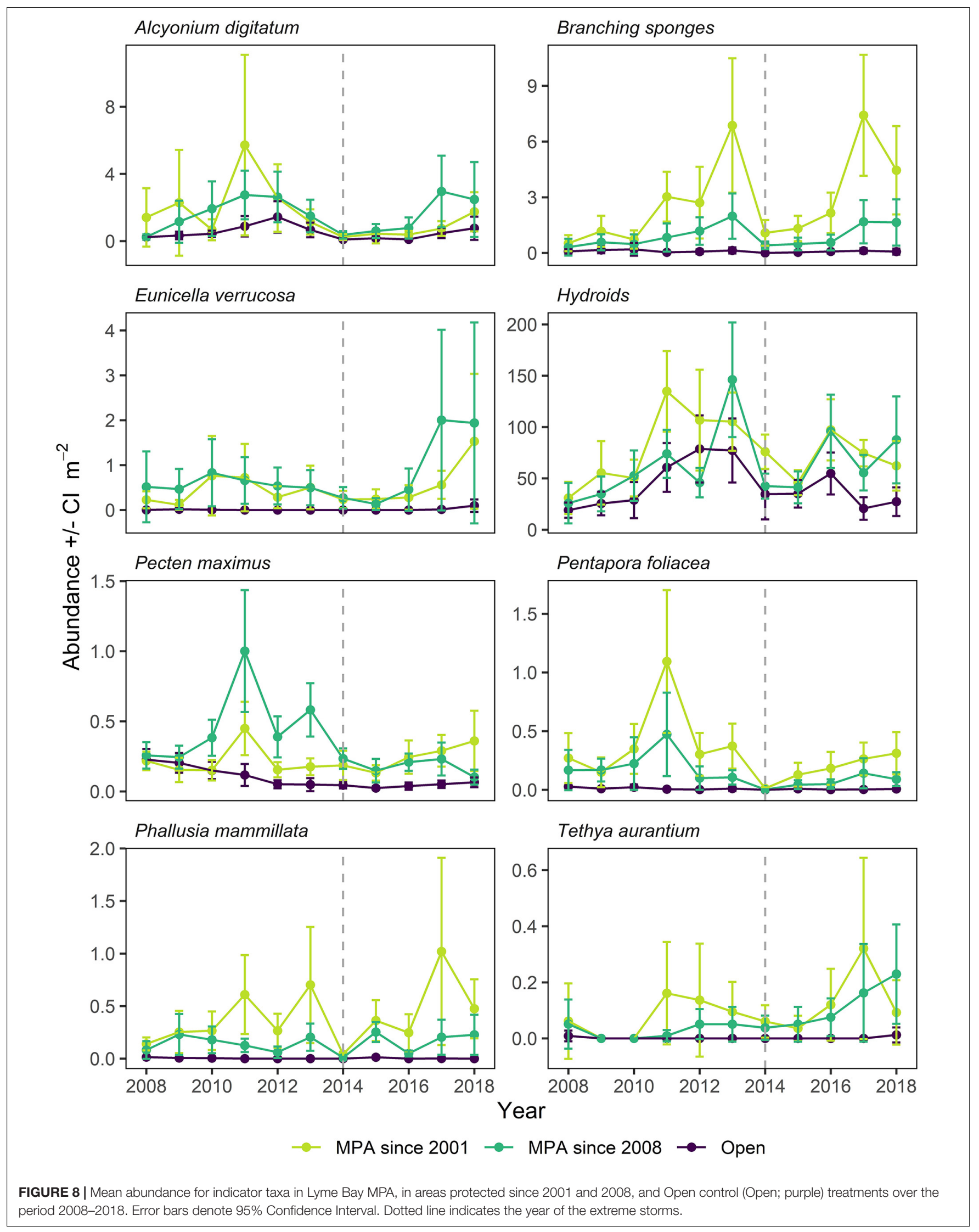


could be overlooked. This is an important consideration when setting or evaluating progress toward conservation goals since setting targets based on a post-storm condition may lead to an underestimate of an ecosystem's species diversity or carrying capacity. The Lyme Bay post-storm recovery trends demonstrate that monitoring in the first 2 years following major storm disturbance will likely lead to conclusion of limited progress toward conservation goals. While limited to a single MPA and one major series of storms, these observations carry significance for monitoring and target setting more widely.

\section{CONCLUSION}

An evaluation of the effect of extreme storm events on epibenthic assemblages has highlighted that MPAs have the capacity to confer rewilding potential and ecological resilience through recovery, but not resistance in benthic communities in coastal areas. Protection of soft sediment habitats within and around MPAs from any human disturbance may well add this resistance, however. Observations of the wave climate within Lyme Bay MPA and other coastal reef MPAs has highlighted that a large proportion of the coastal reef MPAs nationally may experience extreme wave conditions likely to impact the benthos. This study has highlighted the magnitude of disturbance which can occur in temperate reef assemblages and underscores the need for frequent monitoring within MPAs in order to establish the likely natural variability and response to extremes within a system. Greater understanding of the relationships between natural disturbance and biological indicators, and the interactions of MPAs with the wider coastal system still requires further research to inform effective ecosystem-based management.

\section{DATA AVAILABILITY STATEMENT}

The raw data supporting the conclusions of this article will be made available by the authors, without undue reservation.

\section{REFERENCES}

Anderson, M. J. (2001). A new method of non-parametric multivariate analysis of variance. Austral. Ecol. 26, 32-46. doi: 10.1111/j.1442-9993.2001. 01070.pp.x

Angeler, D. G., and Allen, C. R. (2016). Editorial: quantifying resilience. J. Appl. Ecol. 53, 617-624. doi: 10.1111/1365-2664.12649

Barbier, E. B., Hacker, S. D., Kennedy, C., Koch, E. W., Stier, A. C., and Silliman, B. R. (2011). The value of estuarine and coastal ecosystem services. Ecol. Monogr. 81, 169-193. doi: 10.1890/10-1510.1

Barnosky, A. D., Hadly, E. A., Bascompte, J., Berlow, E. L., Brown, J. H., Fortelius, M., et al. (2012). Approaching a state shift in Earth's biosphere. Nature 486, 52-58. doi: 10.1038/nature11018

Bates, A. E., Cooke, R. S. C., Duncan, M. I., Edgar, G. J., Bruno, J. F., BenedettiCecchi, L., et al. (2019). Climate resilience in marine protected areas and the 'Protection Paradox.'. Biol. Conserv. 236, 305-314. doi: 10.1016/J.BIOCON. 2019.05.005

Bicknell, A. W. J., Sheehan, E. V., Godley, B. J., Doherty, P. D., and Witt, M. J. (2019). Assessing the impact of introduced infrastructure at sea with cameras:

\section{AUTHOR CONTRIBUTIONS}

ES, LH, and MA conceived this research and wrote the manuscript. ES, LH, AC, AR, and BD gathered the data. ES, LH, and $\mathrm{BD}$ analysed the data. All authors contributed to the article and approved the submitted version.

\section{FUNDING}

This research was funded by Natural Environment Research Council (NERC NE/M005208/1), Natural England, DEFRA, Pig Shed Trust, South West Inshore Fishermen's Association, South Western Fish Producer's Organisation, and the European Maritime Fisheries Fund.

\section{ACKNOWLEDGMENTS}

We acknowledge the Lyme Bay fishermen who supported this research with providing vessels and expert knowledge and the Blue Marine Foundation, Devon and Severn and Southern Inshore Conservation and Fisheries Authorities, Natural England, Devon and Dorset Wildlife Trusts, Department of the Environment, Food and Rural Affairs and the Marine Management Organisation for working together to deliver an effective Marine Protected Area. We also thank all the volunteers, students, and UoP technical staff who have contributed to this research since 2008 .

\section{SUPPLEMENTARY MATERIAL}

The Supplementary Material for this article can be found online at: https://www.frontiersin.org/articles/10.3389/fmars. 2021.671427/full\#supplementary-material

Supplementary Table 1 | Similarity percentage (SIMPER) comparison of Lyme Bay Marine Protected Area (MPA) to Open controls. Species representing the top $20 \%$ dissimilarity between treatments presented.

a case study for spatial scale, time and statistical power. Mar. Environ. Res. 147, 126-137. doi: 10.1016/j.marenvres.2019.04.007

Birchenough, S. N. R., Reiss, H., Degraer, S., Mieszkowska, N., Borja, Á, BuhlMortensen, L., et al. (2015). Climate change and marine benthos: a review of existing research and future directions in the North Atlantic. . WIREs Clim. Chang. 6, 203-223. doi: 10.1002/wcc.330

Bradshaw, C., Collins, P., and Brand, A. R. (2003). To what extent does upright sessile epifauna affect benthic biodiversity and community composition? Mar. Biol. 143, 783-791. doi: 10.1007/s00227-003-1115-7

Bray, J. R., and Curtis, J. T. (1957). An ordination of the upland forest communities if southern Wisconsin. Ecol. Monogr. 27, 325-349. doi: 10.2307/1942268

Bricheno, L. M., Wolf, J., and Aldridge, J. (2015). Distribution of natural disturbance due to wave and tidal bed currents around the UK. Cont. Shelf Res. 109, 67-77. doi: 10.1016/J.CSR.2015.09.013

Cahill, B., and Lewis, A. W. (2014). "Wave period ratios and the calculation of wave power," in Proceedings of the the 2nd Marine Energy Technology Symposium, $1-10$.

Channel Coastal Observatory (2017). Channel Coastal Observatory. Available online at: http://www.channelcoast.org/ (accessed October 18, 2017) 
Choat, J. H., Ayling, A. M., and Schiel, D. R. (1988). Temporal and spatial variation in an island fish fauna. J. Exp. Mar. Bio. Ecol. 121, 91-111. doi: 10.1016/00220981(88)90249-3

Clarke, K., and Warwick, R. (2001). Change in Marine Communities: An Approach to Statistical Analysis and Interpretation. Plymouth: PRIMER-E.

Clarke, K., Chapman, M., Somerfield, P., and Needham, H. (2006). Dispersionbased weighting of species counts in assemblage analyses. Mar. Ecol. Prog. Ser. 320, 11-27. doi: 10.3354/meps320011

Connell, J. H. (1978). Diversity in tropical rain forests and coral reefs. Science 199, 1302-1310. doi: 10.1126/science.173.3999.771

Connell, J. H., and Keough, M. J. (1985). "Disturbance and patch dynamics of subtidal marine animals on hard substrata," in The Ecology of Natural Disturbance and Patch Dynamics, (Academic Press, Inc.), 125-151. Available online at: http://www.sciencedirect.com/science/article/pii/ B9780125545204500137. doi: 10.1016/b978-0-12-554520-4.50013-7 (accessed July 7, 2021)

Connell, J. H., Hughes, T. P., and Wallace, C. C. (1997). A 30-year study of coral abundance, recruitment, and disturbance at several scales in space and time. Ecol. Monogr. 67, 461-488. doi: 10.1890/0012-9615(1997)067[0461:aysoca]2.0. $\mathrm{co} ; 2$

Cowen, R. K., Agegian, C. R., and Foster, M. S. (1982). The maintenance of community structure in a central California giant kelp forest. J. Exp. Mar. Bio. Ecol. 64, 189-201. doi: 10.1016/0022-0981(82)90152-6

Davies, B., Holmes, L., Rees, A., Attrill, M., Cartwright, A., and Sheehan, E. (2021). 'Ecosystem approach to fisheries management workshow switching from mobile to static fishing gear improves populations of fished and non-fished species inside a marine protected area. J. Appl. Ecol. doi: 10.1111/1365-2664. 13986

Duarte, C. M., Agusti, S., Barbier, E., Britten, G. L., Castilla, J. C., Gattuso, J. P., et al. (2020). Rebuilding marine life. Nature 580, 39-51. doi: 10.1038/s41586020-2146-7

European Commission (2008). Directive 2008/56/EC of the European Parliament and of the Council Establishing A Framework For Community Action in the Field of Marine Environmental Policy (Marine Strategy Framework Directive).

Fragkopoulou, E., Serrão, E. A., Horta, P. A., Koerich, G., and Assis, J. (2021). Bottom trawling threatens future climate Refugia of Rhodoliths globally. Front. Mari. Sci. 7:1246. doi: 10.3389/fmars.2020.594537

Gerlach, A. S. A., Ekstrøm, D. K., and Eckardt, P. B. (1976). Filter feeding in the hermit crab Pagurus bernhardus. Oecologia 24, 257-264. doi: 10.1007/ bf00345477

GESAMP (2018). Joint Group of Experts on the Scientific Aspects of Marine Environmental Protection. Report of the Forty-Fourth Session of GESAMP. Switzerland:

Graham, N. A. J., Bellwood, D. R., Cinner, J. E., Hughes, T. P., Norström, A. V., and Nyström, M. (2013). Managing resilience to reverse phase shifts in coral reefs. Front. Ecol. Environ. 11:541-548. doi: 10.1890/ 120305

Harris, L. G., Ebeling, A. W., Laur, D. R., and Rowley, R. J. (1984). Community recovery after storm damage: a case of facilitation in primary succession. Science 224, 1336-1338. doi: 10.1126/science.224.4655.1336

Holbrook, S. J., Kingsford, M. J., Schmitt, R. J., and Stephens, J. S. Jr. (1994). Spatial and temporal patterns in assemblages of temperate reef fish. Am. Zool. 34, 463-475. doi: 10.1093/icb/34.3.463

Holling, C. S. (1973). Resilience and stability of ecological systems. Annu. Rev. Ecol. Syst. 4, 1-23. doi: 10.1146/annurev.es.04.110173.000245

Jackson, E., Langmead, O., Barnes, M., Tyler-Walters, H., and Hiscock, K. (2008). Identification of Indicator Species to Represent the Full Range Of Benthic Life History Strategies for Lyme Bay and the Consideration of the Wider Application for Monitoring of Marine Protected Areas. Report to the Department of Environment, Food and Rura. Plymouth. Available online at: http://randd.defra. gov.uk/Document.aspx?Document=MB0101_7946_IR.pdf (accessed July 7, 2021).

Jentsch, A., Kreyling, J., and Beierkuhnlein, C. (2007). A new generation of climatechange experiments: Events, not trends. Front. Ecol. Environ. 5:365-374. doi: 10.1890/1540-9295(2007)5[365:angoce]2.0.co;2

Joint Nature Conservation Committee (2017). UK-Wide Digital GIS Datasets for Internationally Designated Sites. Available online at: http://jncc.defra.gov.uk/ protectedsites/SACselection/gis_data/ (accessed October 17, 2017)
Kendon, M. (2015). Editorial: the UK storms of winter 2013/2014. Weather 70, 39-40. doi: 10.1002/wea.2474

Lehmann, J., Coumou, D., Frieler, K., Eliseev, A. V., and Levermann, A. (2014). Future changes in extratropical storm tracks and baroclinicity under climate change. Environ. Res. Lett. 9:084002. doi: 10.1088/1748-9326/9/8/084002

Posey, M., Lindberg, W., Alphin, T., and Vose, F. (1996). Influence of storm disturbance on an offshore benthic community. Bull. Mar. Sci. 59, 523-529.

R Core Team (2019). R: A Language and Environment for Statistical Computing. Available online at: https://www.r-project.org/ (accessed July 7, 2021).

R Core Team (2021). R: A Language and Environment for Statistical Computing. Available online at: https://www.r-project.org/ (accessed July 7, 2021).

Rees, S. E., Sheehan, E. V., Stewart, B. D., Clark, R., Appleby, T., Attrill, M. J., et al. (2020). Emerging themes to support ambitious UK marine biodiversity conservation. Mar. Policy 117:103864. doi: 10.1016/j.marpol.2020. 103864

Renaud, P. E., Riggs, S. R., Ambrose, W. G., Schmid, K., and Snyder, S. W. (1997). Biological-geological interactions: storm effects on macroalgal communities mediated by sediment characteristics and distribution. Cont. Shelf Res. 17, 37-56. doi: 10.1016/0278-4343(96)00019-2

Scheibling, R. E., Kelly, N. E., and Raymond, B. G. (2009). Physical disturbance and community organization on a subtidal cobble bed. J. Exp. Mar. Bio. Ecol. 368, 94-100. doi: 10.1016/j.jembe.2008.10.017

Seitz, R. D., Wennhage, H., Bergström, U., Lipcius, R. N., and Ysebaert, T. (2014). Ecological value of coastal habitats for commercially and ecologically important species. ICES J. Mar. Sci. 71, 648-665. doi: 10.1093/icesjms/fst152

Sheehan, E. V., Cousens, S. L., Nancollas, S. J., Stauss, C., Royle, J., and Attrill, M. J. (2013a). Drawing lines at the sand: evidence for functional vs. visual reef boundaries in temperate marine protected areas. Mar. Pollut. Bull. 76, 194-202. doi: 10.1016/j.marpolbul.2013.09.004

Sheehan, E. V., Stevens, T. F., and Attrill, M. J. (2010). A quantitative, nondestructive methodology for habitat characterisation and benthic monitoring at offshore renewable energy developments. PLoS One 5:e14461. doi: 10.1371/ journal.pone.0014461

Sheehan, E. V., Stevens, T. F., Gall, S. C., Cousens, S. L., and Attrill, M. J. (2013b). Recovery of a temperate reef assemblage in a marine protected area following the exclusion of towed demersal fishing. PLoS One 8:e83883. doi: 10.1371/ journal.pone.0083883

Sheehan, E. V., Vaz, S., Pettifer, E., Foster, N. L., Nancollas, S. J., Cousens, S., et al. (2016). An experimental comparison of three towed underwater video systems using species metrics, benthic impact and performance. Methods Ecol. Evol. 7, 843-852. doi: 10.1111/2041-210X.12540

Solandt, J. L., Mullier, T., Elliott, S., and Sheehan, E. (2020). Achieving True Site Integrity: Moving From 'Feature-Based'to 'whole-Site'Management of MPAs Post-Brexit. Estuarine, Coastal and Shelf Science. doi: 10.1111/2041-210x.12540

Stevens, T. F., Sheehan, E. V., Gall, S. C., Fowell, S. C., and Attrill, M. J. (2014). Monitoring benthic biodiversity restoration in Lyme Bay marine protected area: design, sampling and analysis. Mar. Policy 45, 310-317. doi: 10.1016/j.marpol. 2013.09.006

Szostek, C., Davies, A., and Hinz, H. (2013). Effects of elevated levels of suspended particulate matter and burial on juvenile king scallops Pecten maximus. Mar. Ecol. Prog. Ser. 474, 155-165. doi: 10.3354/meps10088

The Lyme Bay Designated Area (Fishing Restrictions) Order (2008). The Lyme Bay Designated Area (Fishing Restrictions) Order Statutory Instrument 2008/1584, Under the Sea Fish (Conservation) Act 1967 (2008).

UNEP-WCMC, and IUCN (2016). Protected Planet Report 2016. How Protected Areas contribute to achieving Global Targets for Biodiversity. Cambridge. Available online at: https://wdpa.s3.amazonaws.com/Protected_Planet_ Reports/2445 Global Protected Planet 2016_WEB.pdf. (accessed July 7, 2021).

UNEP-WCMC, and IUCN (2020). Marine Protected Planet. Cambridge. Available online at: www.protectedplanet.net (accessed May 15, 2020)

Vaselli, S., Bulleri, F., and Benedetti-Cecchi, L. (2008). Hard coastal-defence structures as habitats for native and exotic rocky-bottom species. Mar. Environ. Res. 66, 395-403. doi: 10.1016/J.MARENVRES.2008. 06.002

Wang, Z., and Dudgeon, D. (2021). Recovery of tropical marine benthos after a trawl ban demonstrates linkage between abiotic and biotic changes. Commun. Biol. 4:212. doi: 10.1038/s42003-021-01732-y 
Wood, S. N. (2003). Thin-plate regression splines. J. R. Statist. Soc. 65, 95-114. doi: 10.1111/1467-9868.00374

Wood, S. N. (2004). Stable and efficient multiple smoothing parameter estimation for generalized additive models. J. Am. Statist. Assoc. 99, 673-686. doi: 10.1198/ 016214504000000980

Wood, S. N. (2017). Generalized Additive Models: An Introduction With R, 2nd Edn.

Woodley, J. D., Chornesky, E. A., Clifford, P. A., Jackson, J. B. C., Kaufman, L. S., Knowlton, N., et al. (1981). Hurricane Allen's impact on Jamaican coral reefs. Science 214, 749-755. doi: 10.1126/science.214. 4522.749

Young, I. R., Zieger, S., and Babanin, A. V. (2011). Global trends in wind speed and wave height. Science 332, 451-455. doi: 10.1126/science. 1197219

Zappa, G., Shaffrey, L. C., Hodges, K. I., Sansom, P. G., and Stephenson, D. B. (2013). A multimodel assessment of future projections of north atlantic and european extratropical cyclones in the CMIP5 climate models. J. Clim. 26, 5846-5862. doi: 10.1175/JCLI-D-12-00573.1
Conflict of Interest: The authors declare that the research was conducted in the absence of any commercial or financial relationships that could be construed as a potential conflict of interest.

Publisher's Note: All claims expressed in this article are solely those of the authors and do not necessarily represent those of their affiliated organizations, or those of the publisher, the editors and the reviewers. Any product that may be evaluated in this article, or claim that may be made by its manufacturer, is not guaranteed or endorsed by the publisher.

Copyright $(2021$ Sheehan, Holmes, Davies, Cartwright, Rees and Attrill. This is an open-access article distributed under the terms of the Creative Commons Attribution License (CC BY). The use, distribution or reproduction in other forums is permitted, provided the original author(s) and the copyright owner(s) are credited and that the original publication in this journal is cited, in accordance with accepted academic practice. No use, distribution or reproduction is permitted which does not comply with these terms. 